\title{
Contexts for Micro-change: The Case of German Zeitnah, Postwendend and Voll
}

\author{
Anneliese Kuhle \\ Institute for English Language and Literature, Free University Berlin, Germany
}

Copyright (C) 2016 by authors, all rights reserved. Authors agree that this article remains permanently open access under the terms of the Creative Commons Attribution License 4.0 International License

\begin{abstract}
In the current debate on language change, the focus on micro-changes has become more prominent [13, $\mathrm{p}$. 221]. One arguable advantage of focusing on instances of change which involve only a relatively small number of structural and/or functional innovations is that the specific circumstances which instigate such change are easier to reconstruct. Moreover, these may be more closely identifiable with the actual usage events speakers and hearers engage in every day. Specifically, this paper deals with three instances of micro-change in Present-day German: the innovation from nahe to zeit+nahe, the development of postwendend as an emphatic temporal modifier, and the emergence of Austrian German voll in discourse-pragmatic function. Each instance is analyzed from a usage-based perspective though in each case different motivating factors for change come into focus. Most importantly for the argument, these factors are invariably based on the considerations of context, not innate cognitive biases. From the cognitive point of view, these findings are taken in support of the claim that linguistic innovations are based on only general cognitive abilities also characteristic of other intentional behaviors such as the handling and innovation of tools.
\end{abstract}

Keywords Language Change, Emergent Grammar, Context, Local Pragmatic Inferences, Language User, Intentionality

"Language is, in other words, to be viewed as a kind of pastiche, pasted together in an improvised way out of ready-made elements."

$[7$, p. 144]

\section{Introduction}

In his much-noticed discussion of the concept of Emergent Grammar, Hopper[7] sharpened the view that grammar does not merely consist of a set of stabilized constructions which can be generalized more or less freely, but that in fact it contains an equal amount of constant irregularities and deviations from previously established "rules" or conventions. One of the most vivid metaphorical depictions of language in this paper is its characterization as historical patchwork, or as Hopper puts it: "Language is, in other words, to be viewed as a kind of pastiche, pasted together in an improvised way out of ready-made elements." [7, p. 144]. Along these lines, Hopper stresses that every single discourse and instance of language use will not merely contain formulaic repetitions of utterances produced elsewhere in the speech community, but that it will just as much contain individualistic compositions and applications of elements serving the language user's most individual needs and purposes of behavior.

In this functionalist notion of the language system, language users are the real tool-makers of linguistic constructions - constructions defined here in a fairly broad sense, subsuming sentential or clausal compositions, elliptical contractions or the composition of complex words. It is for their own individual needs that they make use of linguistic materials and it is for the sake of understanding the intentions of others and of fulfilling their own that they interpret and recruit these materials in a context-dependent manner. As Hopper also points out, this usage-oriented recruitment of linguistic means may be either favored or hampered by the inherent properties inherited from previous usages. Hence, the felicity of a construction can never be predicted on its own, without a given context and purpose of behavior. Moreover, its felicity can also never be predicted without taking into consideration the already existent usage properties of an item under the particular circumstances in which it is used.

In the current paper, I seek to apply this notion of emergent language structures with a focus on micro-change. The aim is to demonstrate how particular historical constellations in natural language use can lead to local disturbances in the interpretation of conventionalized means, and how these may be resolved by certain modifications of these items either in terms of their formal makeup or meaningful interpretation.

The reason for referring to the developments observed 
here as micro-changes has to do with the fact that they are fairly recent developments in the German language and, moreover, because the total sum of changes reported for each individual item is very small compared to that of other processes of change traceable over many centuries and historical stages of language development. The term is deliberately taken from Traugott[13], and the aim of this analysis is also to support the more general credo of Traugott's review article that onset contexts for change must and can very well be substantiated for all types of linguistic expressions.

In the sections below, I will consider each type of onset context in turn. Section 2 deals with the German adjective zeitnah(e) and its recent emergence as a temporal-deictic expression. In Section 3, I turn to the discussion of German postwendend and compare its etymology and usage to its near-synonym umgehend 'immediately; at once'. Section 4 finally deals with the adverb voll in Austrian German where it has assumed a discourse marker function clearly absent in standard High German. In Chapter 5 I summarize my findings and relate them to considerations of context and cognition more generally.

\section{Expressive Clarity and Empathetic Cognition: German Zeitnah}

The production of meaningful utterances in language use is context-dependent. Whether an utterance like "Eat this!" will be meaningful in a given speech event depends on the circumstances under which it is being used. It depends on the previous interaction between speaker and hearer and the degree of common ground that has been established between them. If no sufficient common ground exists, the expression will not establish reference and communication will fail. Naturally, language users possess rich linguistic repertoires by which they are able to furnish many different kinds of speech contexts. If "Eat this!" does not yield sufficient reference, more explicit expressions like "Eat the cake!" or "Eat the cake that's in the fridge!" might be successful. A crucial insight to be gained from this consideration is that linguistic expressions are in their very function directed at the mental states of our interlocutors, not our own, nor at the physical world to which they refer. If we consider processes of language change, it is important to find evidence that this directedness of language use also shows in the implementation of lexical or grammatical innovations.

The recent emergence of German zeitnah as a time-deictic expression can provide an illustration of this fact. The form is a complex word, an adjective, consisting of the two elements zeit- 'time' and -nah 'close; near'. It has emerged throughout the twentieth century, mostly in formal speech styles (journalistic writing), and appears in two different meaning variants which in Kuhle[10] are referred to as metaphorical-descriptive and time-deictic, respectively. Examples (1) and (2) illustrate each usage. The metaphorical-descriptive meaning (ex. 1) is based on the conceptualization of time as a large space occupied by a society or historical era (e.g., the time of the Romans, the present times etc.) and that of proximity (-nah 'close') in terms of similarity, topicality and appropriateness. The time-deictic interpretation (ex. 2), on the other hand, depends on the more dynamic conceptualization of time as a linear scale counted in minutes, hours, days etc.; in this context, the other element -nah translates into temporal, not metaphorical proximity.

(1) Es war eine sehr zeitnah gestaltete it was a very time.nearly staged Aufführung

show

'This was a very timely/contemporarily staged show.'

(2) Der Beschluss sollte zeitnah the resolution should.have time.nearly umgesetzt werden; implemented become; inzwischen ist aber schon wieder meanwhile is however already again viel Zeit verstrichen. much time gone.by

'The resolution was supposed to have been implemented very soon; meanwhile, however, a lot of time has passed by.'

What is of special interest for our present discussion is the transition from nah 'near' to zeitnah lit. 'time+near' and the latter's emergence as a time-deictic expression. The reason why it deserves special interest is that the form nah already expresses temporal proximity in certain constructions without the additional modifier element zeit-. Hence, the question arises under what conditions of speaking there might have arisen a need for this innovation to zeitnah. We begin with a few examples illustrating the use of nah 'near; close' as a temporal expression.

(3)

$$
\begin{aligned}
& \text { in naher Zukunft } \\
& \text { in near(.the) future } \\
& \text { 'in the near future' }
\end{aligned}
$$

(4) Weihnachten liegt nahe an Silverster Christmas lies close to New Year's Eve 'Christmas is close to New Year's Eve.'

In both utterances, (3) and (4), nahe is clearly interpreted with a temporal meaning. It conveys that some event or referent is located temporally close to either the moment of utterance (cf. ex. 3) or else some other point in time specified by the surrounding discourse (cf. ex. 4). In this way, nahe can occur with quite a number of other temporal referents (e.g., ein naher Termin 'a soon-to-be date', die nahe Vergangenheit 'the near past' etc.) without ever failing to express proximity in the temporal domain. However, this expressive clarity of the term breaks down in contexts where nahe may be interpreted other than just with a temporal meaning. Such disturbances begin to arise as soon as the 
form is used with non-temporal referents. Consider for example the collocations under (5) which, given no further context, prefer non-temporal interpretations. Given these collocates, zeitnahe remains the only option if temporal proximity - as opposed to other types of proximity - is meant to be conveyed (cf. ex. 6).

(5) nahe Berichterstattung/Kontrolle/Entscheidungen close news coverage control decisions 'detailed/faithful news coverage / control; close/ narrow decision-making'

(6) zeitnahe Berichterstattung/Kontrolle/Entscheitime.close news coverage control decidungen

sions

'speedy news coverage / control / decision-making'

Such data are suggesting that the structural innovation undergone by German nahe (to zeitnahe) may have arisen out of the need for speakers and hearers to properly agree on the dimension of proximity to be associated with this form. Though its temporal meaning can be inferred clear enough in combination with prototypical temporal referents - mainly because alternative interpretations are not feasible - other pragmatic inferences would be invited by its usage in combination with non-temporal referents. One option of dealing with this disturbance for the temporal reference of nahe was thus surely the functional modification of this term by way of compounding, which is very productive in Present-day German [3].

In this context, analogical transfer might have played a crucial role in motivating this innovative step. Thus, one can observe that the compounding pattern 'noun+nahe' is quite common in Present-day German, yielding such common formations as praxisnah lit. 'practice.near' ('practical; with practical orientation'), realitätsnah lit. 'reality.near' ('realistic'), volksnah lit. 'people.near' ('down-to-earth; in touch with the people'), ortsnah lit. 'location.near' ('local') or more recently also bildungsnah lit. 'education.near' ('well-educated'). In terms of sheer numbers, the pattern is not highly productive, but it is productive and especially with antonymic pairs like bildungsnah and bildungsfern ('un-educated') has gained considerable frequency over past decades in formal educational jargon and the public speech sector (journalism, politics).

An intriguing possibility explored in some detail in Kuhle[10] is that the temporal-deictic meaning variant of zeitnah(e) arose from semantic remotivation, that is, was recycled as a compound form to express temporal proximity from an earlier, already existing form zeit+nahe which did not relate temporal but metaphorical proximity (cf. ex. 1). This is at least supported by quantitative data from the German DWDS corpus: in the mid-twentieth century, the form was mostly just used in the sense of 'contemporary; modern; topical' and was thus very common in magazine columns dealing with literary or artistic performances or other cultural achievements like architecture, furniture, public law and education. The temporal-deictic variant, by contrast, only appeared in later decades and only gained comparable frequency to the other variant towards the turn of the century.

A conceivable alternative to the formation of zeitnah(e) as a way to avoid ambiguity would of course have been to neglect the form in potentially ambiguous speech contexts and to replace it long-term by other temporal expressions such as baldig 'soon-to-be', schnell 'quick; speedy' or umgehend 'prompt'. However, other external factors may have disfavored such an extension [10]. In particular, the observation that the form primarily arose in speech contexts to do with economic policy making, and from thence quickly spread into the political jargon, suggests that language users were in need of a temporal expression which was not taken from everyday speech and which could express certain temporal relations according to their own needs and purposes of action. Most early usages of zeitnah(e) are thus related to contract management and the announcement of supposedly rigid and highly committed time schedules of public figures and institutions. In this context, more conventionalized and colloquial expressions of time would have diminished the sense of urgency and commitment intended by such formal and often public speech acts. Moreover, in many of these contexts of usage, zeitnah(e) also carries an aspect of expressive modality which does not only convey emphasis and urgency but also politeness and a sense of appeasement towards the interlocutor and/or public audience.

In Harnisch[4], such instances of structural enrichment as exemplified here with German zeitnah(e) are referred to as linguistic strengthening ("sprachliche Verstärkung"). What makes them different from other processes of change is that the structural modification of an item does not motivate a change but rather the preservation of meaning already associated with a given form. In the case of zeitnahe one can observe that the simplex form nahe already encodes temporal proximity in some contexts of usage, however that its temporal aspect is never explicitly expressed by any part of its formal composition. Rather, the temporal meaning is always imposed on it via pragmatic inferencing whenever it occurs with prototypical temporal referents. Thus, an inventive way of preserving this meaning aspect even under unfavorable conditions where pragmatic inferencing becomes more ambiguous is to explicitly encode it on the relevant speech item (zeit+nahe). In Harnisch's terms this is an instance of 'content seeks form' [4, p. 14].

To conclude, the case of German zeitnah 'promptly; soon' suggests an instance of micro-change where the maxim of expressive clarity was compromised by the different possibilities of interpreting the less complex form nahe under certain conditions of usage. ${ }^{1}$ This local disturbance of the temporal interpretation of nahe was, on the one hand, due to the fact that some referents allowed more freedom in attributing proximal meaning to nahe,

1 It is thus taken for granted here that language users' speech is guided by the ultimate goal (maxim) that they will be understood by others. For a more detailed discussion of the 'maxim of clarity', see Haspelmath[5], pp. 1055-1057. 
beyond the temporal domain. On the other hand, it was equally attributed to the fact that nahe had already assumed non-temporal proximal meanings in other thematic contexts of usage. Consequently, there seems to have arisen a bias to use and interpret nahe temporally only in connection with inherently temporal referents, while using and interpreting it metaphorically in combination with referents not necessarily or primarily associated with temporal qualities. The resulting difficulty of nevertheless transcending the temporal meaning of nahe into those contexts where other proximal interpretations would be favored could thus only be overcome by an act of innovative linguistic pasting (nahe 'near' $\rightarrow$ zeitnahe 'near in time') [7].

\section{World Knowledge and Metaphorical Extension: German Postwendend}

In this section, we turn to the temporal meaning of postwendend and how it is becoming gradually extended in language use to include temporal reference which is primarily emphatic and conveying a sense of urgency in direct speaker-hearer-interaction. The basic claim is that this sense of urgency associated with the form cannot simply be derived from its contexts of usage but must rather be attributed to its etymological origins and the schematic concept which formed the original starting point of its development as temporal modifier. To make my point, I draw on comparative data from the partially synonymous expression umgehend.

The history of the adverb postwendend 'immediately; at once' goes back to the nineteenth century $[8$, p. 715$)]$ and is conspicuously synchronous with that of the near-synonym umgehend 'immediately; at once' [8, p. 940]. The latter is far more frequent in day-to-day usage and also, as we will see below, more productive than its counterpart postwendend. Nevertheless, the etymology of both these formations is very similar. They both go back to the nineteenth century and, in terms of reference, the practices of the postal service by means of a coach and horses $[8,12]$. They both derive from phrasal expressions equivalent to the English expression 'by return of (the) post'. The only difference is that they are built on different literal descriptions of the same event: postwendend was motivated by the phrasal expression mit wendender Post 'with the turning of the post', while umgehend was based on the phrasing mit umgehender Post 'with the around-going post' (cf. ex. 7-8).

(7)

$$
\begin{aligned}
& \text { a. mit wendender Post } \\
& \text { with turning(.the) post } \\
& \text { 'to answer with the turning post' } \\
& \text { b. postwendend antworten } \\
& \text { post.turning(ly) answer } \\
& \text { 'to answer post-turningly' }
\end{aligned}
$$

\section{b. postwendend antworten}

antworten

answer
a. mit
umgehender
Post
with
around.going(.the)
post
antworten
answer

'to answer with the around-going post'
b. umgehend (mit der Post) antworten around.going(ly) (with the post) answer 'to answer around-goingly (with the post)'

As is shown by the b-sentences in (7) and (8), respectively, the phrasal expressions were thus replaced by more economical, single-word formations which were, as before, used in adverbial position. In the case of postwendend, two phrasal elements were taken in composition with one another: the nominal head Post 'post; postal service' and the participle form wendend (adj.) of the verb wenden 'turn around'. In the case of umgehend, only the participle form of the complex verb umgehen 'go around (lit. around-go)' was recruited as the new temporal modifier.

What is most relevant here for our present discussion is the fact that both complex word formations were apparently built on the same real-world experience - namely, the practices and accommodations of the postal service; however, they were chosen by speakers as alternative metaphors for basically the same temporal meaning (= the immediacy or rapidity of some action, initially directly connected to the use of the postal services). This is not to say that language users necessarily intended to express different meanings by either relying on postwendend or umgehend in the first place. In fact it is more likely that they simply sporadically invented these two variants alongside of each other and that consequently, at this initial stage, there was no marked difference in meaning.

At the same time, however, it must be noted that the metaphorical meanings (schematic depictions) evoked by the two expressions are not identical; in fact they differ rather strikingly. Postwendend, by way of its underlying verbal meaning 'turn', depicts a bidirectional event schema where the post moves in two directions, from A to B and from B back again to A. Umgehend, on the other hand, rather depicts the process of moving around in different directions, from one place to another, so that consequently there is no special focus on the ultimate endpoints of such movement. These different concepts (event schemas) underlying each form are visualized in Figure 1a and 1b, respectively.

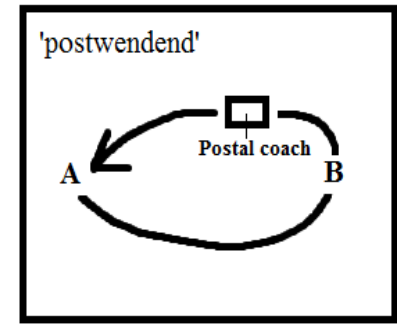

Figure 1a

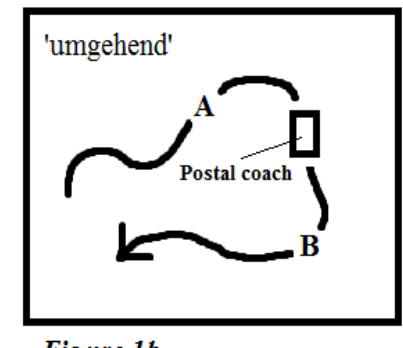

Figure 1b
Figure 1. The different conceptualizations of the dynamic event descriptions implicated by the adverbs poswendend (1a) and umgehend (1b), respectively.

The consequences of these different conceptual starting points, that is, different literal depictions of basically the 
same real-world scenario, can be seen in the subsequent developments undergone by each form. As was mentioned above, umgehend is today far more frequent and colloquial in usage than postwendend. If we search for the most frequent and typical verb collocates of umgehend in the German DWDS corpus, a wide range of dynamic event descriptions proves compatible with this form (cf. Table 1). It does not play a role whether umgehend expresses temporal immediacy in reference to events that describe bidirectional, reactive event schemas (e.g., 'deny', 'reject', 'answer') or whether it refers to actions inherently unprompted by previous incidents or actions (e.g., 'initiate', 'report', 'inform' etc.).

Table 1. Typical verb collocates of German umgehend 'immediately; at once'. The data are taken from the DWDS-word profile 3.0 [accessed 12/13/14] from the Digital Dictionary of the German Language (= Digitales Wörterbuch der deutschen Sprache, DWDS, http://www.dwds.de/).

\begin{tabular}{|c|c|c|c|c|}
\hline Rank & $\begin{array}{c}\text { Verb } \\
\text { collocate }\end{array}$ & Translation & Association & Frequency \\
\hline 1 & dementieren & disclaim, deny & 8.58 & 230 \\
\hline 2 & einleiten & initiate, introduce & 7.14 & 77 \\
\hline 3 & informieren & inform & 6.88 & 142 \\
\hline 4 & ankündigen & announce & 6.6 & 147 \\
\hline 5 & melden & report & 6.45 & 150 \\
\hline 6 & beenden & terminate, finish & 6.44 & 90 \\
\hline 7 & weiterleiten & forward & 6.43 & 36 \\
\hline 8 & freilassen & release & 6.42 & 36 \\
\hline 9 & aufnehmen & accomodate & 6.31 & 160 \\
\hline 10 & vorlegen & present & 6.29 & 89 \\
\hline 11 & hinweisen & indicate & 6.26 & 345 \\
\hline 12 & einstellen & adjust, cease, hire & 6.22 & 120 \\
\hline 13 & einreichen & submit & 6.21 & 36 \\
\hline 14 & distanzieren & distance & 6.18 & 41 \\
\hline 15 & ablehnen & reject & 6.16 & 161 \\
\hline 16 & antworten & answer & 6.12 & 87 \\
\hline
\end{tabular}

This lack of collocational restrictions for umgehend can be nicely contrasted with the much more biased associative pattern for postwendend. Hence, it shows a much clearer preference for reactive, action-reaction event schemas like answering, responding, giving back, retaliating etc., and is only rarely found, at least in written language, with non-reactive event descriptions (cf. Table 2; the data is again taken from the German DWDS corpus).

Table 2. Typical verb collocates of German postwendend 'immediately; at once'. The data are taken from the DWDS-word profile 3.0 [accessed
12/13/14] from the Digital Dictionary of the German Language (= Digitales Wörterbuch der deutschen Sprache, http://www.dwds.de/).

\begin{tabular}{|c|c|c|c|c|}
\hline Rank & Verb collocate & Translation & Association & Frequency \\
\hline 1 & zurückschicken & $\begin{array}{l}\text { return, send } \\
\text { back }\end{array}$ & 9.03 & 36 \\
\hline 2 & revanchieren & return a favor & 7.97 & 13 \\
\hline 3 & kontern & counter, retort & 7.22 & 19 \\
\hline 4 & zurückschlagen & retaliate & 6.96 & 13 \\
\hline 5 & dementieren & disclaim & 6.65 & 26 \\
\hline 6 & zurückerhalten & receive back & 6.36 & 7 \\
\hline 7 & zurückgeben & give back & 6.35 & 19 \\
\hline 8 & ausgleichen & compensate & 5.76 & 20 \\
\hline 9 & zurückkommen & come back & 5.68 & 29 \\
\hline 10 & antworten & answer & 5.57 & 43 \\
\hline 11 & zurückweisen & repudiate & 4.79 & 19 \\
\hline 12 & schicken & send & 4.38 & 22 \\
\hline 13 & kassieren & $\begin{array}{c}\text { collect } \\
\text { (money) }\end{array}$ & 4.28 & 9 \\
\hline 14 & beantworten & answer & 3.81 & 10 \\
\hline 15 & ablehnen & reject & 3.31 & 19 \\
\hline 16 & reagieren & react & 3.21 & 28 \\
\hline
\end{tabular}

This comparative data suggests that from the very beginning ( $19^{\text {th }}$ century onwards), German language users have been sensitive to the different conceptual foundations of both forms, notwithstanding their identical inferential meanings associated with temporal immediacy of action. As both forms were extended beyond their original context of reference, they remained affiliated with different event schemas as they inherently captured different aspects of the original real-world incident: the turning of the post and its heading back towards the end/starting point (Figure 1a) versus the going around of the post until incidentally reaching its end/starting point (Figure 1b). As a result, postwendend has until today retained a much stronger association with reactive, bidirectional event descriptions, while umgehend allows a much broader spectrum of dynamic event schemas, including but not limited to the reactive type.

Interestingly, however, this basic difference shows less clearly in less formal speech styles of German. In both spoken discourse and (informal) internet communication, postwendend seems often to be preferred over umgehend even in contexts where no action-reaction schema is implied (cf. ex. 9-10).

(9) Ich bleibe solange auf [...] bis mir die Augen auf dem Sofa zufallen. Dann gehe ich postwendend ins Bett und kann sofort einschlafen. (Google)

'I stay awake until my eyes fall shut [...]. Then I 
immediately go to bed and am able to sleep.'

(10) Damit solltest du postwendend einen Arzt aufsuchen! (Google)

'You should immediately go to the doctor with that!'

In many of these usages, postwendend appears to have a more emphatic aspect than would otherwise be conveyed by umgehend. Especially in contexts where exclamations are made or directives issued in direct speaker-hearer-interaction, postwendend seems to carry more emphasis compatible with the illocutionary force of the utterance. In such cases, the primary referential meaning of the term seems to be exploited on a new level of reference, where it does not so much reflect on the actual arrangement of the events in a reactive event schema (action $\mathrm{x}$ being done in immediate response to a prompting action y), but rather where it is deliberately recruited by the speakers to impress on the addressee that something should be done as immediately as possible, as though it were an incident preceded by some prompting action. An interesting side effect of such deliberate extensions in usage is that the form thereby gradually receives more opaqueness regarding its real-world reference. As language users recruit this form more and more often in utterances referring to non-reactive event schemas, its original referential meaning becomes more weakened and starts to gain common ground with that of other expressions like umgehend or sofort 'immediately; at once'. As a result, it becomes less prominent in regard to its referential meaning but gains new characteristics as a special stylistic device.

I therefore contend that the case study on German postwendend 'immediately; at once' demonstrates the crucial role played by literal depictions of real-world scenarios and how these can serve as the foundation for productive metaphorical extensions in subsequent language use. Of particular interest is the juxtaposition of postwendend with its near-synonym umgehend which is very similar in meaning but far more frequent and habitual across different styles and registers of German. Even though both adverbs developed in reference to the same real-world scenario (i.e., the practices of the postal service during the $19^{\text {th }}$ century), they still encoded, from the very beginning, two alternative viewpoints of the same spatiotemporal scenario. Postwendend lit. 'post-turningly' was built on the viewpoint that the postal service moves between two endpoints and the inference that the quickest way of posting something is by catching it directly on its return path. This metaphor of thinking and speaking about temporal immediacy was thus built on a bidirectional (there-and-back-again) event schema which has subsequently persisted in the usage of the form postwendend with mostly reactive event descriptions. Umgehend lit. 'around-goingly', by contrast, was built on the viewpoint that the postal service moves around from one place to another, thereby eventually reaching all its intended destinations. In this depiction of the postal practice, there is no immediate reference of its going in two directions and thus no focus on the bidirectional aspect of it, nevertheless the same implication of temporal immediacy can be derived from it. The way language users subsequently generalized this form to refer to all sorts of dynamic event descriptions, not just the reactive type, thus indicates that its conceptual foundation evoked other, less selective associations in speakers than did that of its less frequent counterpart postwendend.

Nevertheless, as an emphatic form, postwendend also occurs increasingly often in contexts where it would not be expected. Thus, speakers also draw on it in contexts where the real-world referent (verbal predication) does not allow an interpretation in terms of the bidirectional event schema. In other words, it is the real-world context in such cases which makes it impossible for language users to literally associate the term with the reactive event schema. Instead, its usage merely conveys the typical force or immediacy of a reactive event schema and thereby simply conveys more emphasis (i.e., a sense of urgency) in the perception of the interlocutor. This reasoning fits well with the observation that this usage of the form is particularly common with informal and direct speaker-hearer-interactions, where emphatic language often plays an important role.

The deliberate transfer of linguistic items beyond their original referential domain is often discussed in the literature under the heading of subjectification [14-15,11]. In such works, the subjective perspective or attitude of the speaker is said to motivate the transfer of an expression from a more referential to a less referential meaning. This transition is made possible by the fact that the language user conceptualizes part of the referential meaning only to him- or herself (subjectively), without seeking external reference, and by only re-applying part of the original meaning to the actual content of the predication. The observed side-effect of such subjectifications of meaning is that the expressions develop into more expressive and discourse-oriented devices which are more indicative of the speaker's attitude towards a proposition rather than its actual referential content (e.g., see Traugott's discussion in [14-15]).

\section{Linguistic Scaffolding and Pragmatic Inferencing: Austrian German Voll}

From the standard High German perspective, Austrian German language users and German speakers of southern federal states like Bavaria display a curious speech variant in colloquial discourses. They use the adjectival expression voll 'full(y)' in a discourse-marking function in affirmative sentences (cf. ex. 11-12). ${ }^{2}$

$$
\begin{aligned}
& \text { (11) A: Hier ist es kälter als in Wien. } \\
& \text { here is it colder than in Vienna } \\
& \text { 'It is colder here than in Vienna.' }
\end{aligned}
$$

2 The data presented in this section are taken from personal interviews (11/2014, 09/2015) with speakers of Austrian German and the Bavarian dialect. 
B: Ja voll.

yes fully

'Yes totally.'

(12) A: Das fühlt sich bestimmt so an weil that feels self surely like.this because der Herbst so warm war. the fall so warm was

'This (weather) surely feels so cold because the fall was so warm.'

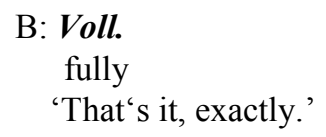

Although for the German native speaker the intended reference becomes immediately clear from the context, it is nevertheless conspicuous and not the way he or she would normally know how to handle the expression in natural discourse. In standard High German, voll is only conventionally used in two functions. As a descriptive adjective, it is used mainly with referents describing, either literally or metaphorically, containers of some shape or form (e.g., a 'glass', 'room', 'book', 'soul' etc.) and in such cases carries the quantifying meaning 'full' (cf. ex. 13).

(13) a. Das Glas ist voll.
the glass is full
'The glass is full.'
b. das volle Glas
the full glass
'the full glass'

Furthermore, it is also frequently used as an intensifying expression with the maximizing meaning of 'extremely', 'completely', 'entirely' or 'totally'. As such it is used adverbially either as the modifier of verbs or adjectives (cf. 14-15).

(14) Das ist voll interessant.
that is fully interesting
'That is extremely interesting.'
(15) Das habe ich voll vergessen.
that have I fully forgot
'I totally forgot [that].'

In this latter function, the form may also occur in response sentences as given previously by the examples (11) and (12) (i.e., Ja voll! 'yes totally'). However, the crucial difference is that in such cases, the form still functions as intensifying expression of some verbal or adjectival predication offered in the previous utterance by the interlocutor. In other words, voll here typically retains narrow scope and only serves as modifier of part of the previous predication, not as emphatic affirmation of the entire speech act. This usage is illustrated by example (16).

\footnotetext{
(16) A: Das ist (voll) peinlich. that is (fully) embarrassing 'That is (very) embarrassing.'
}

\author{
B: Ja voll. \\ yes full(y) \\ 'Yes totally' = 'Yes, you're right, that is very \\ embarrassing'
}

After having thus established the basic difference between the colloquial usage of voll in Austrian (and Southern) German and its habitual usage in standard High German, we may turn to a possible historical scenario for this functional innovation in the southern dialect. To begin with, we may of course assume that voll in Austrian German also serves the two functions attributed to standard High German, namely descriptive (quantifying) and intensifying. Furthermore, we may also assume that if used in the intensifying function, the form can likewise appear in affirmative responses as exemplified under (16). In this way, we need not make any extra assumptions regarding the circumstance that in Austrian German the form (also) occurs in short affirmative responses when used with a wide-scope, discoursepragmatic function (cf. ex. 11-12). Rather, we simply extrapolate from the empirical facts in German that the expression already habitually occupies this linguistic environment solely based on its function as intensifier.

This leaves us with the question of how the intensifying usage could have provided the platform for further extension into the more wide-scope, discourse-pragmatic function. At least one plausible scenario is that speakers incidentally began to transfer the usage of affirmative voll-responses to utterances offering no true collocates for the modifying effect of voll. Thus, for example, voll is no typical intensifier of comparative formations such as älter 'older', kälter 'colder' or angenehmer 'more pleasant' though it is fully compatible with its non-graded counterparts (i.e., voll alt 'very old', voll kalt 'very cold', voll angenehm 'very pleasant'). This alone could lead addressees to make new pragmatic inferences about the emphatic reference of the term voll, along the lines that if the term cannot reasonably be interpreted as a modifier of some part of a preceding predication, it must be interpreted as a modifier of the entire predication.

The depiction of this particular scenario of micro-change fits well with what Evans and Wilkins[2] and Heine[6] have discussed under the label of bridging contexts. These are generally defined as contexts of usage where a given item may still be interpreted in its original function but where moreover other meanings may also become feasible options for their interpretation. In a further step, the item may then end up being used in more critical contexts where the optional meaning variant is strongly preferred over the more habitual meaning. Under such novel conditions of usage, the former pragmatic inference may thus become selectively strengthened in its own right and subsequently serve as a new platform for further analogical transfer within this novel domain.

The verbal exchange in (11) would give a good example of this kind of 'bridging context'. In this speech event, it becomes at least controversial - due to the comparative construction - to interpret voll as a modifier of kälter 'colder', 
and consequently suggestive for the interpreter to seek the emphatic reference of this form elsewhere, that is, on a higher structural speech level. Of course, the possibility of a canonical intensifying meaning cannot per se be ruled out. If Person A were to utter a sentence like "Hier ist es voll kälter als in Wien." ('It is totally colder here than in Vienna'), Person B could, after all, embrace the collocation 'voll + comparative' as acceptable and thus simply confirm it in his/her elliptical response ( $\mathrm{Ja}$ voll!, Voll!). However, given the general markedness of this co-occurrence and given a co-text where voll is not explicitly included in A's construction, a possible alternative inference on either side would be that the term assumes a wider scope of emphatic meaning which lies in the affirmation of a given utterance more generally as a whole. Note, however, that in such a scenario of change, the reasoning of speaker and addressee must not necessarily go hand in hand with one another. ${ }^{3}$ The addressee alone may favor the wide-scope interpretation, while the speaker may still adhere to the narrow-scope interpretation. This would mean that speaker and addressee take liberties in different directions when interpreting this form in the so-called bridging context. The speaker may take the liberty and intend voll as a modifier of the comparative form, thereby willingly stretching the existing formal convention. The addressee, on the other hand, may not conform to this speaker attitude and instead take the liberty in another direction by simply inferring a wider scope. Subsequently, he/she could adhere to this interpretation and carry it over into novel utterances with novel addressees. In this way, the wide-scope variant would not be instigated by the original speaker of the utterance (Person $\mathrm{B}$ ) but the addressee (Person A).

Let me concede that the reasoning offered in this section is speculative and that there is no direct empirical proof that speakers of Austrian German came by their innovative usage of voll in the way depicted here. Nevertheless, it is built on rather plausible, usage-based assumptions regarding the incidental extension of a form from one function to another. These assumptions do not only highlight the fact that certain contexts of usage allow language users to make novel pragmatic inferences regarding the interpretation of a form. Rather, they also take into consideration the previous patterns of usage already associated with the form in its original function. By taking such primary distributions into consideration, it becomes clear that a form may already possess many functional and structural properties subsequently also shared - and thus in a way simply inherited - by the innovative speech variant. At the same time, certain conventionalized restrictions in such primary usage patterns may then also become instrumental in motivating sudden reinterpretations of a form in favor of a new functional variant. As the example of Austrian German voll demonstrates, such reinterpretations may then depend as much on the linguistic (structural) co-text as on the possibility for novel pragmatic inferencing.

3 I thank an anonymous referee for drawing my attention to this particular aspect.
To conclude, a consideration of the normal distributional pattern of voll in intensifying function (cf. standard High German) provides us with a very reasonable platform for its further extension into the discourse-pragmatic domain. The merit of this reconstruction lies in the fact that the actual step from intensifying to discourse-pragmatic function is a fairly small one. Moreover, it can be conveniently accounted for on the basis of pragmatic inferencing on the side of language users. The only structural input to this process of change comes from a certain usage bias previously conventionalized for this form in its intensifying function. It can thus be shown how voll would not normally be used as modifier together with comparative formations, presumably because both forms (intensifier, comparative) designate different types of gradation not easily compatible with one another. If the intensifying form is thus used in affirmative phrases ( $\mathrm{Ja}$ voll!) in response to utterances containing the comparative formation, language users are at least likely to reinterpret the reference of this form, transferring its emphatic aspect onto a broader scope of reference. The result is that the form does not intensify only part of the proposition made (voll + adjective) but rather serves as intensifier of the proposition as a whole (voll + entire sentence).

\section{Conclusions}

The current paper has dealt with processes of micro-change under the functional perspective. The consideration of three instances of change in Present-day German (zeitnah; postwendend; voll) has uncovered quite different circumstances and constellations of usage, and hence could focus on different factors (pragmatic, cognitive, linguistic) which may influence the functional and structural modification of linguistic means. By including the notion of 'emergent grammar' [7] into the discussion, it was possible to elaborate more explicitly on the metaphor of language as a historical patchwork, or in Hopper's own terms "as a kind of pastiche, pasted together in an improvised way out of ready-made elements" [7, p. 144]. The crucial insight to be gained from this functional conception is that language users themselves are the inventors of novel linguistic constructions whether these consist of structural enrichments, metaphorical extensions or functional reinterpretations of already existent speech variants.

This conclusion is relevant for the cognitive perspective on language, because inventions are never built on any preexisting cognitive biases in the acting individual. Instead, they are the result of on-going, context-dependent and goal-oriented negotiations with the environment. In the specific case of language, this general type of cognition is empathetic, that is, it is functionally aimed at the mental frames (ideas, thoughts, feelings, volitional attitudes) of other acting individuals. As Traugott[15] puts it: "the meaning changes are the result of language use in strategic interaction and goal-oriented activity," and "the changes [...] [are] primarily showing evidence of speakers injecting 
themselves into the flow of speech, creating coherent discourses [...]" (15, pp. 514-515). Hence, the structural and functional modifications we observe are the result of this particular dialogic rationale between speaker and addressee which is aimed at communicating beyond different subjective mind-sets. This contention can be directly correlated with our empirical findings. For example, in the case of German zeitnah there would be no demand for the structural innovation observed (i.e., compounding) if language users were not concerned about the perspectives and mental frames beyond their own. In inner monologue, language users can be perfectly content with using vague expressions like nahe, no matter whether these describe the temporal, spatial or metaphorical dimension. Yet, the fact that such meanings need to get across and enter the thoughts of other individuals, make more explicitness (e.g., in the shape of zeitnahe) a necessary ingredient to successful communication.

Moreover, this conclusion is relevant for the cognitive perspective on language, because it demonstrates that the shared meanings between speaker and addressee are themselves invariably built on the extra-linguistic context and the pragmatically structured real-world knowledge in reference to which linguistic communication takes place. In this context, the phenomenon of metaphorical extension is of particular interest. It constitutes the very process by which new meanings are created out of old meanings in novel contexts. It shows how linguistic means are not symbolically referential but how in fact they are perceptually referential in the sense that they are grounded in schematic representations of the environment which are born out of the individuals' nonlinguistic, intentional interactions with the world. This logic of metaphorization and transfer was made particularly clear by the example of German postwendend and umgehend. At the outset, the temporal meanings of both adverbial expressions were tightly linked to complex notions of a sociocultural practice within the community, namely the postal service. Based on this shared world knowledge, the concrete meaning of temporal immediacy could be derived. Initially this meaning was only conveyed in reference to the practice itself. Subsequently, however, the pragmatic inferences of temporal immediacy became dissociated from the concrete event and transferred onto other real-world scenarios equally allowing this temporal qualification. Such selective dissociations from the primary percepts of the environment, and their stepwise modifications through re-interpretations in novel contexts of usage, are simply symptomatic of general cognition under the control of intentional goal orientations, but nevertheless still constitute clear instances of functionally oriented cognition.

On a still more general note, this type of cognition underlying the innovation of linguistic means is also characteristic of the invention and handling of tools. What makes an object a real 'tool' at the hands of an individual is the fact that it does not remain dedicated to one and the same function but that it is constantly put to new functional uses depending on previous affordances of the tool and the intentions of the acting individual. The function of a stick for reaching will be discovered under only concrete conditions of problem solving. However, what eventually makes this object a real tool in the mind of the beholder is when he/she subsequently discovers that he/she may transfer it to all sorts of other problem settings not equaling the original context of discovery. Within such modes of transfer, even a simple object like a stick may evolve from a tool for reaching to a tool for spearing, or even become a symbol of social prestige. It is under this gestalt-psychological perspective in the tradition of Köhler[9], Bühler[1] and Vygotsky[16] that Hopper's notion of linguistic pasting should be understood.

\section{Acknowledgements}

I would like to thank an anonymous referee for his/her immensely helpful and constructive criticism of an earlier version of this paper. All remaining errors are my own.

\section{REFERENCES}

[1] Bühler, Karl. 1934. Sprachtheorie: Die Darstellungsfunktion der Sprache. [Theory of Language: The representational function of language] Jena: Fischer.

[2] Evans, Nicholas and Wilkins, David. 2000. In the mind's ear: The semantic extensions of perception verbs in Australian languages. Language 76, 546-592.

[3] Fleischer, Wolfgang and Barz, Irmhild. 2012. Wortbildung in der deutschen Gegenwartssprache. [Word Formation in the Contemporary German Language] 4th edition. Berlin: Walter de Gruyter.

[4] Harnisch, Rüdiger. 2010. Zu einer Typologie sprachlicher Verstärkungsprozesse. [Towards a typology of linguistic strengthening processes] In Rüdiger Harnisch (ed.) Prozesse sprachlicher Verstärkung, 3-23. Berlin: Walter de Gruyter.

[5] Haspelmath, Martin. 1999. Why is grammaticalization irreversible? Linguistics 37(6), 1043-68.

[6] Heine, Bernd. 2002. On the role of context in grammaticalization. In Ise Wischer and Gabriele Diewald (eds.) New Reflections on Grammaticalization, 83-101. Amsterdam/Philadelphia: John Benjamins.

[7] Hopper, Paul. 1987. Emergent Grammar. Berkeley Linguistic Society 13, 139-157.

[8] Kluge, Friedrich. 2002. Etymologisches Wörterbuch der deutschen Sprache. [Etymological Dictionary of the German Language] 24th edition. Berlin/NY: Walter de Gruyter.

[9] Köhler, Wolfgang. 1971. Die Aufgabe der Gestaltpsychologie [The Task of Gestalt Psychology] Berlin/NY: Walter de Gruyter.

[10] Kuhle, Anneliese. 2015. Semantic remotivation and idiomatization through functional recontexualization: A corpus-based study on the history of German zeitnah(e) 'promptly; very soon'. Studies in Media and Communication 
3(2), 51-61.

[11] Langacker, Ronald W. 1990. Subjectification. Cognitive Linguistics 1(1), 5-38.

[12] Pfeifer, Wolfgang. 1993. Etymologisches Wörterbuch des Deutschen. [Etymological Dictionary of German] 2nd edition. Berlin: Akademie-Verlag Berlin. [Accessed electronically via the DWDS Platform at http://www.dwds.de/, 12/13/14]

[13] Traugott, Elizabeth C. 2012. The status of onset contexts in the analysis of micro-changes. In Merja Kytö (ed.) English Corpus Linguistics: Crossing Paths, 221-255. Amsterdam/NY: Rodopi.
[14] Traugott, Elizabeth C. 1995. Subjectification in grammaticalisation. In Dieter Stein and Susan Wright (eds.) Subjectivity and Subjectivisation, 31-54. Cambridge: Cambridge University Press.

[15] Traugott, Elizabeth C. 1990. From less to more situated in language: The unidirectionality of semantic change. In Sylvia Adamson, Vivien Law and Nigel Vincent (eds.) Papers from the Fifth International Conference on English Historical Linguistics, 496-517. Amsterdam: John Benjamins.

[16] Vygotsky, Lev. 1978. Mind in society: The development of higher psychological processes. Cambridge, MA: Harvard University Press. 